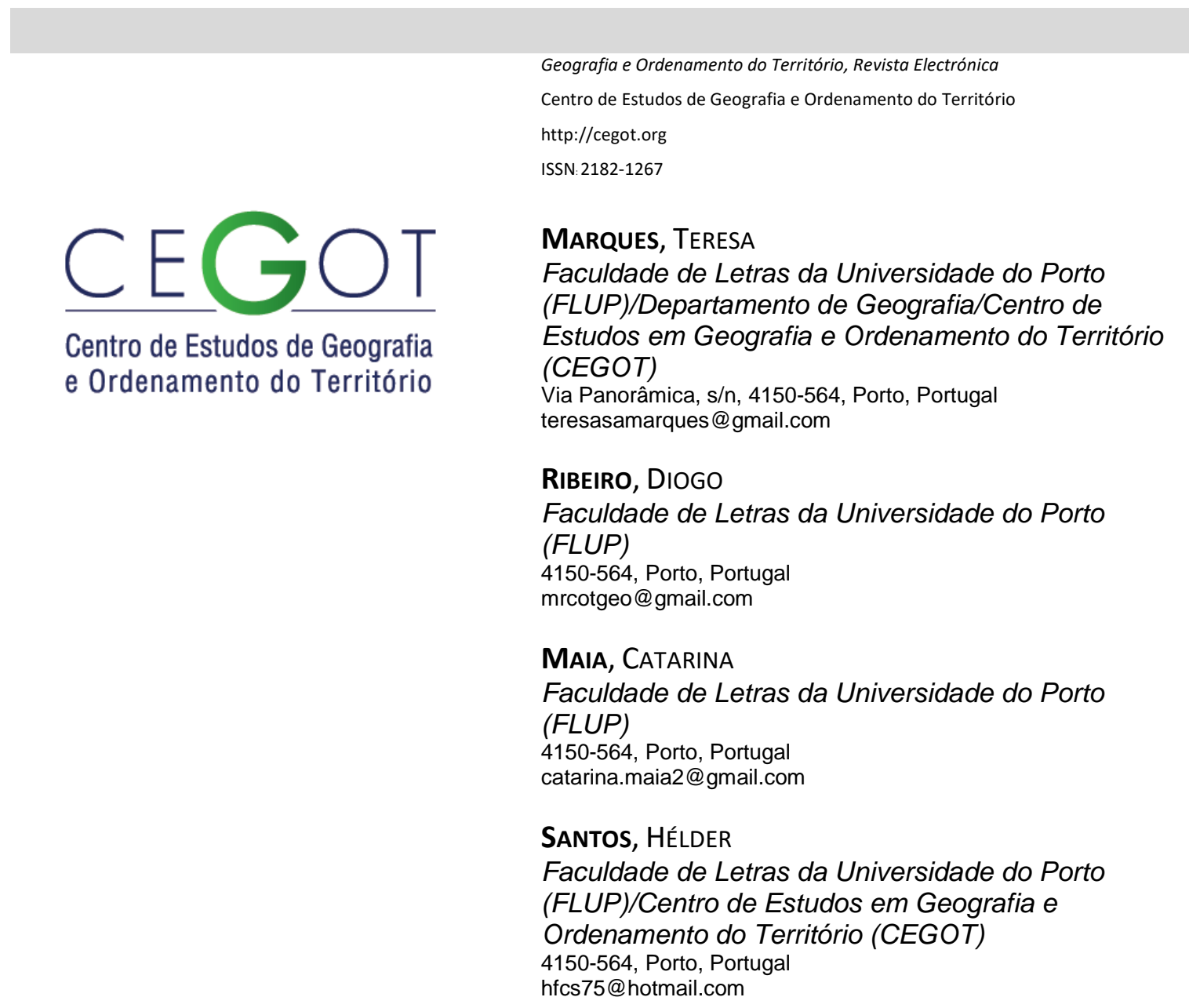

\title{
Nascer é envelhecer: uma perspetiva demográfica evolutiva e territorial na construção do futuro de Portugal ${ }^{1}$
}

\author{
To be born is to age: an evolutionary and territorial demographic perspective \\ in the construction of the future of Portugal
}

Referência: Marques, Teresa et al. (2016). Nascer é envelhecer: uma perspetiva demográfica evolutiva e territorial na construção do futuro de Portugal. Revista de Geografia e Ordenamento do Território (GOT), n.으 10 (dezembro). Centro de Estudos de Geografia e Ordenamento do Território, p. 207-231, dx.doi.org/10.17127/got/2016.10.010

\footnotetext{
${ }^{1}$ Este artigo desenvolve a comunicação intitulada "A demografia na construção de uma visão temporal e territorial de Portugal", apresentada no "V Congresso Português de Demografia - A Crise Demográfica: Um País em Extinção?", 6 e 7 de outubro de 2016, Fundação Calouste Gulbenkian, Lisboa.

Trabalho cofinanciado pelo Fundo Europeu de Desenvolvimento Regional (FEDER) através do COMPETE 2020 Programa Operacional Competitividade e Internacionalização (POCI) e por fundos nacionais através da FCT, no âmbito do projeto POCI-01-0145-FEDER-006891 (Refa FCT: UID/GEO/04084/2013).
} 


\section{RESUMO}

A evolução da população é atualmente considerada como um dos principais desafios dos países europeus. Esta análise retrata uma visão temporal e geográfica da demografia, de forma a refletirmos os desafios ancorados no tempo e no território. Portugal sempre superou as tendências demográficas ao longo da sua história, as mudanças em termos reprodutivos e os efeitos das migrações (internas e externas). A nível local o que mais explica a situação demográfica não é a dinâmica natural, mas a mobilidade, e isso será ainda mais evidente nos próximos anos. O país superou as altas taxas de mortalidade e os ciclos de vida ficaram mais longos, aumentou a eficiência produtiva e passou a necessitar de menos nascimentos para obter o mesmo stock populacional, teve de suportar os impactos da emigração e agora necessita de apostar na atratividade se pretender manter a sua dimensão populacional.

Palavras-chave: Dinâmicas Populacionais; Envelhecimento; Revolução Reprodutiva; Portugal.

\section{ABSTRACT}

Population growth is currently one of the major challenges facing European countries. This analysis puts forward a temporal and geographical view of demography, intended to portray the challenges rooted in time and territory. Over its history, Portugal has always overcome its demographic trends, the changes in reproductive rates, and the effects of migrations (internal and external). At the local level, the main reason explaining the demographic situation is not natural dynamics, but rather mobility, which will tend to become even more evident in the coming years. The country overcame high mortality rates, life cycles became longer, production increased in efficiency, and less births were required to obtain the same levels of population stock. It also had to contend with the impacts of emigration. Portugal now has to invest in its attractiveness if it intends to maintain its population size.

Keywords: Population Dynamics; Aging; Reproductive Revolution; Portugal.

\section{Enquadramento}

O debate contemporâneo centra-se mais na "estrutura" do que no "volume" da população, sobretudo no envelhecimento da população, e o foco está na necessidade de mudar a estrutura etária. O enfoco no "optimum" demográfico (Dasgupta, 1969) tem uma função economista. Existia o pressuposto de que há um volume de população ótima, que era desejável para alcançar. Para os economistas clássicos, o tamanho da população era uma variável integrada nas equações em torno do equilíbrio entre o trabalho, os salários e a riqueza. Alfred Sauvy $(1979 ; 2001)$ evidenciou a necessidade de se promover o natalismo no 
Estado francês para prevenir o declínio nacional face à Alemanha. Sauvy, com grande prestígio institucional e científico, dedicou toda a sua vida a consolidar a noção de "vieillisement démographique" (Sauvy, 1979; 2001). Seguindo Julio Pérez Díaz isto é uma metáfora, porque as populações não envelhecem, não nascem, crescem e morrem, sendo o termo "envelhecimento" enganador, pois qualifica negativamente uma mudança na estrutura de uma população.

A Teoria da Revolução Reprodutiva reúne numa única teoria as duas transições demográficas (Maclnnes e Pérez Díaz, 2008; 2009). Aproveita a capacidade explicativa da demografia e coloca-a num lugar nuclear da modernização social. Tudo isto se obtém transferindo o protagonismo da perspetiva dos stocks para a perspetiva geracional. Substituem-se as estruturas de idades transversais pela dinâmica das idades nos ciclos de vida, e presta-se mais atenção às relações causais existentes entre a mortalidade e a fecundidade a partir de uma perspetiva intergeracional.

Assim, podem-se quantificar as mudanças históricas na "eficiência reprodutiva" e analisar a sua relação com muitas outras mudanças sociais evidentemente vinculadas. Os papéis da mulher, as relações de género, os padrões de convivência, as estruturas familiares, inclusivamente o próprio envelhecimento demográfico, são explicados, hoje-em-dia, pela cultura, pelos valores, pela economia política e até pelas ideias religiosas.

O nosso entendimento é que tem havido alguma incapacidade em evidenciar o impacto das dinâmicas reprodutivas em todos esses âmbitos. Esta perspetiva vincula a mudança reprodutiva com as outras mudanças sociais, as sanitárias e epidemiológicas, as educativas e laborais, as residenciais, as da mobilidade, as dos estilos e da qualidade de vida. Assim, a demografia tem um papel na explicação das mudanças sociais e, por isso, contribui para uma melhor compreensão e um melhor planeamento das políticas relacionadas com as populações (como as políticas sociais, de saúde, das pensões, da educação e as económicas).

As dinâmicas demográficas podem integrar contributos de muitas áreas do conhecimento social. A conceção das populações enquanto stocks dá, assim, lugar a uma demografia dos "sistemas reprodutivos intergeracionais", que tratam as populações como entes dinâmicos, históricos e geográficos, integrados em ciclos de vida completos, não sendo simples 
agregados atemporais e aterritoriais. A mudança demográfica vivida pela humanidade desde o século XVIII é bem conhecida pelos demógrafos, mas tem sido descrita sobretudo por indicadores transversais ("Teoria da Transição Demográfica", TTD) mas, seguindo Julio Pérez Díaz, ignorando a natureza sistémica e longitudinal da reprodução humana.

O que é determinante na eficiência reprodutiva é o número de anos que um indivíduo vive (duração da vida), numa perspetiva longitudinal. Portanto, a mortalidade nas sucessivas gerações é central. Um sistema reprodutivo será tanto mais eficiente quanto menor número de nascimentos precisar para manter uma determinada população. Logo, a combinação entre a fecundidade e a sobrevivência é decisiva. Neste sentido, o importante é maximizar o número de indivíduos que sobrevivem para lá do início da sua vida reprodutiva. Depois, o foco está no tempo necessário para os indivíduos constituírem família e criarem os seus filhos (Pérez Díaz, 2002).

No entanto, se as populações em idade de procriar diminuem (porque emigraram) ou aumentarem (porque imigraram), isso irá ter impactos determinantes na evolução da população. E aqui a análise também tem de ser longitudinal, analisando os sistemas reprodutivos intergeracionais, porque os que saem e os que entram têm estruturas etárias diversificadas. Aqui emerge claramente a dimensão territorial, porque há territórios que ganham e há outros que perdem, e alguns são perdedores ou ganhadores persistentemente ao longo de décadas.

Face a este enquadramento conceptual, este artigo pretende demonstrar como é determinante o território nas análises da evolução da população, seguindo uma perspetiva sistémica e longitudinal da reprodução humana, pois as geografias incorporam as dinâmicas intergeracionais que acompanham os processos de desenvolvimento dos diferentes territórios. Iniciamos o artigo com uma análise longitudinal dos stocks de população em termos globais e em termos territoriais. Em seguida, analisamos de que forma os ciclos de vida em Portugal se tornaram mais longos, fazendo uma análise intergeracional entre 1950 e 2011 e perspetivando para 2040. Depois, analisa-se de que forma os ciclos de vida longos se repercutem em estruturas etárias mais dilatadas e analisa-se a eficiência reprodutiva em termos territoriais. Por fim, cruzam-se as abordagens e faz-se uma reflexão refletindo os desafios. 


\section{Evolução da população portuguesa}

Seguindo a conceção da evolução da população enquanto stock, a população portuguesa aumentou até 2011 (figura 1). No período dos descobrimentos a população contava com 1 milhão de indivíduos, em finais do século XIX, éramos cerca de 5 milhões e no último censo da população mais de 10 milhões, apesar de uma notável diminuição da fecundidade. No século passado, registaram-se algumas crises refletindo a 1a Guerra Mundial e os volumes de emigração dos anos sessenta. Para o futuro, as tendências demográficas mostram um país em perda de população. E não é um fenómeno conjuntural, mas uma tendência clara que vai atravessar a maior parte do território nacional.

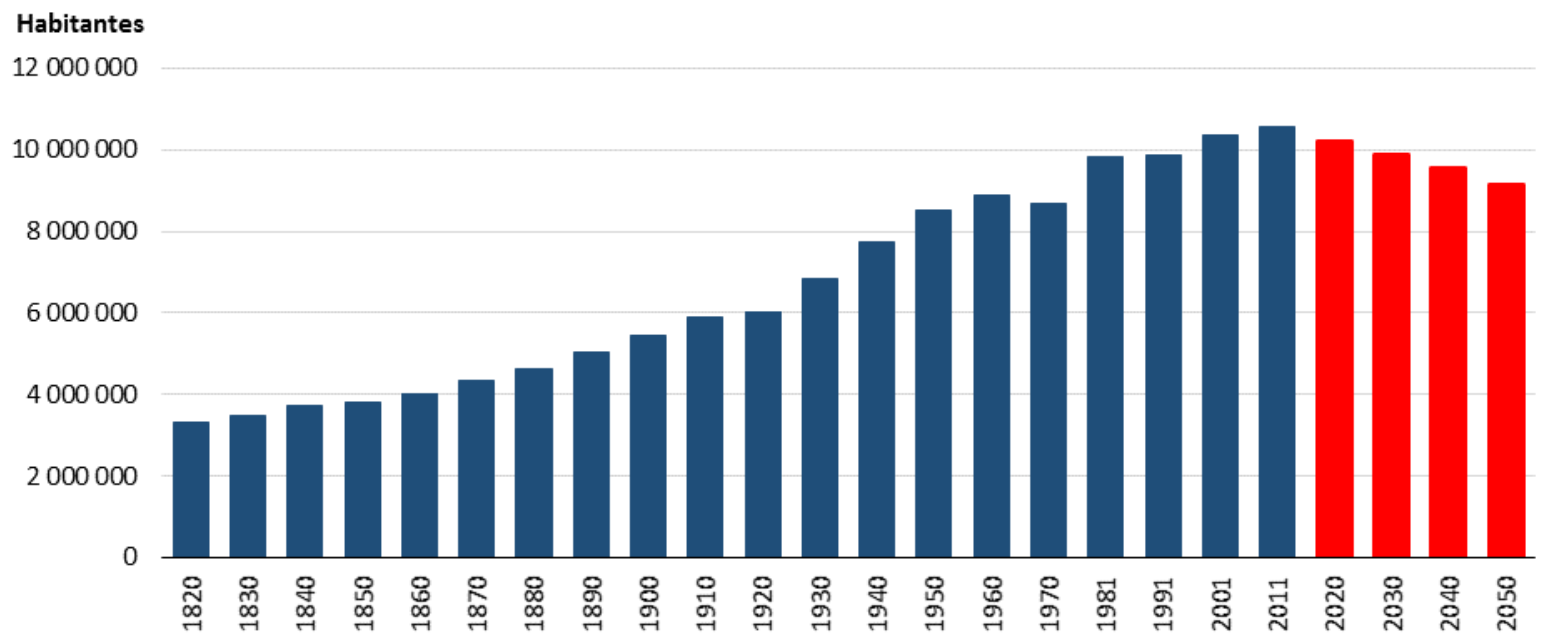

Figura 1 - População residente efetiva e estimada, em Portugal (1820-2050).

Fonte: Elaboração própria. Dados INE (Censos e Estimativas Anuais da População Residente); OCDE (2015); Castro et al. (2015).

A geografia da evolução dos stocks manifesta um comportamento espacial e temporal muito heterogéneo (entre 1950 e 2011) (figura 2). Mas há uma verdade que é estrutural, uma grande parte do território nacional tem vindo progressivamente a perder os seus stocks populacionais ao longo de décadas. E estas dinâmicas negativas não se invertem com facilidade, porque são territórios que têm vindo insistentemente a perder população, sobretudo em idade fértil. Uma grande parcela do território nacional, nos anos sessenta viu partir os mais jovens e os ativos, e os potencialmente mais férteis demograficamente. 

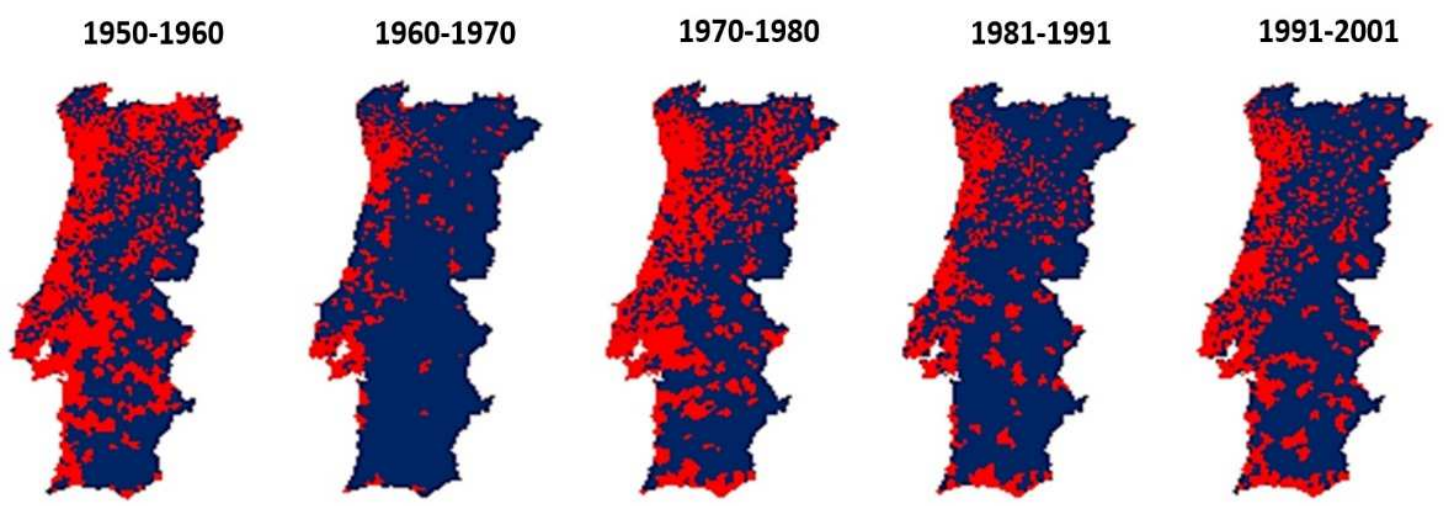

2001-2011

Figura 2 - Dinâmicas positivas e negativas, por freguesias (1950-2011).

Fonte: Elaboração própria. Dados INE (Censos de 1950, 1960, 1970, 1981, 1991, 2001 e 2011).
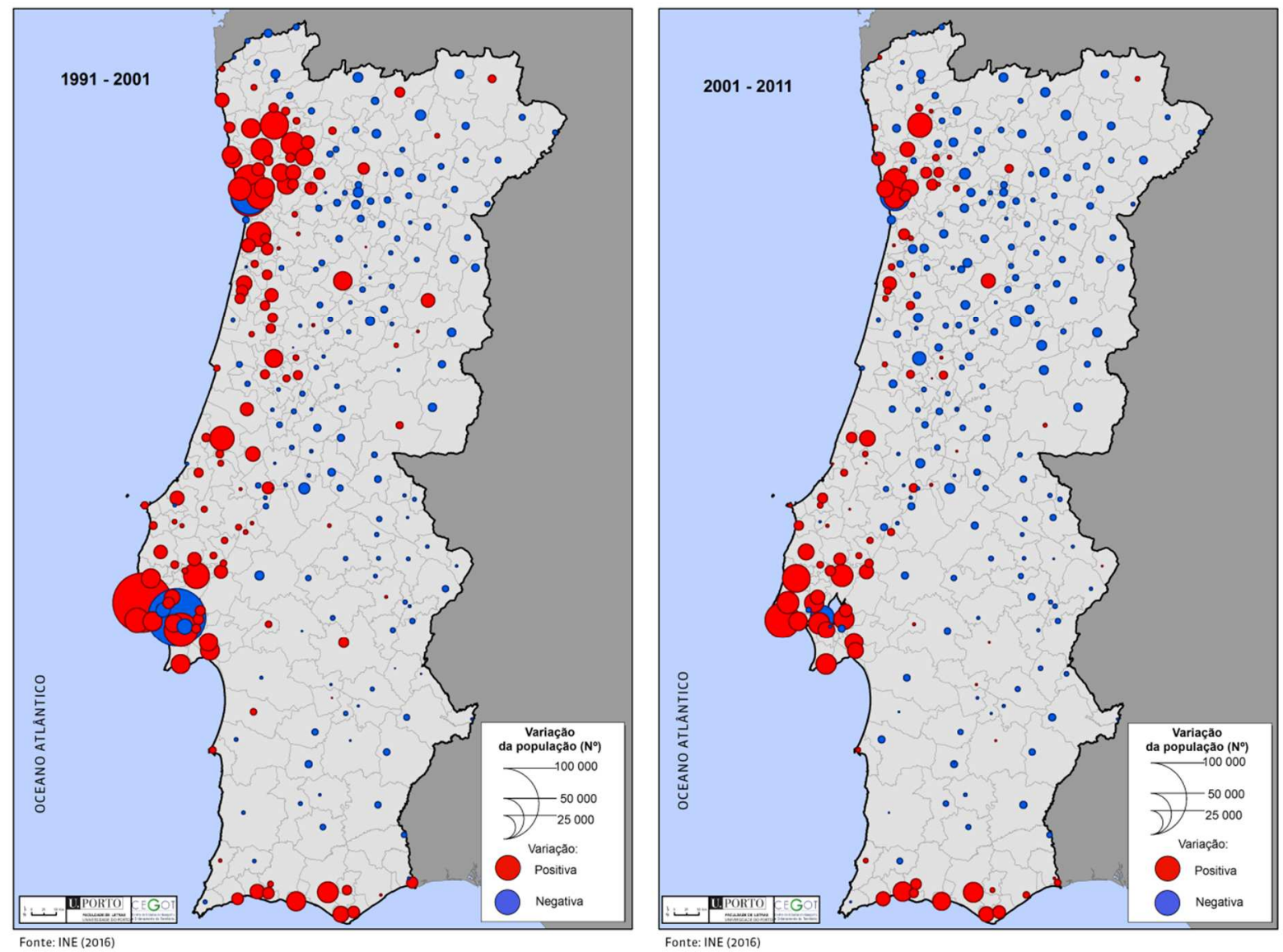

Figura 3 - Variação absoluta da população portuguesa, por concelhos (1991-2001 e 2001-2011). Fonte: Elaboração própria. Dados INE (Censos de 1991, 2001 e 2011). 
A dinâmica populacional na última década já mostra um país tendencialmente a retrair-se (figura 3). Na década de noventa do século $X X$, as duas regiões metropolitanas ainda estavam em expansão populacional, embora as freguesias centrais de Lisboa e do Porto estivessem em clara perda. No Norte destaca-se um extenso território a aumentar os seus stocks populacionais, de Viana do Castelo até Aveiro-Coimbra. Mais a sul emerge positivamente a Região de Leiria e a metrópole de Lisboa com as periferias urbanas em franco crescimento populacional. Depois evidencia-se a faixa litoral do Algarve. Fora deste contexto territorial, só as freguesias urbanas das principais cidades médias conseguem aumentar de população, nomeadamente em Bragança, Chaves, Mirandela, Vila Real, Viseu, Guarda, Castelo Branco, Évora, entre outras.

$\mathrm{Na}$ primeira década do século XXI, os territórios em perda alastraram e as perdas intensificaram-se, nomeadamente no Noroeste, e algumas cidades médias passam também a perder população ou a aumentar menos. Só a Região de Lisboa e o Algarve mostram algum dinamismo.

\section{Um ciclo de vida cada vez mais longo}

O ciclo de vida dos indivíduos tem vindo a aumentar progressivamente e nunca foi tão longo em Portugal (figura 4). As pessoas vivem mais anos porque têm melhores condições de vida e um maior acesso a cuidados de saúde, que lhes permite usufruir de um maior bem-estar e serem cidadãos ativos por mais tempo. Atualmente o desafio deixou de ser viver mais anos, mas viver mais anos com qualidade de vida. 


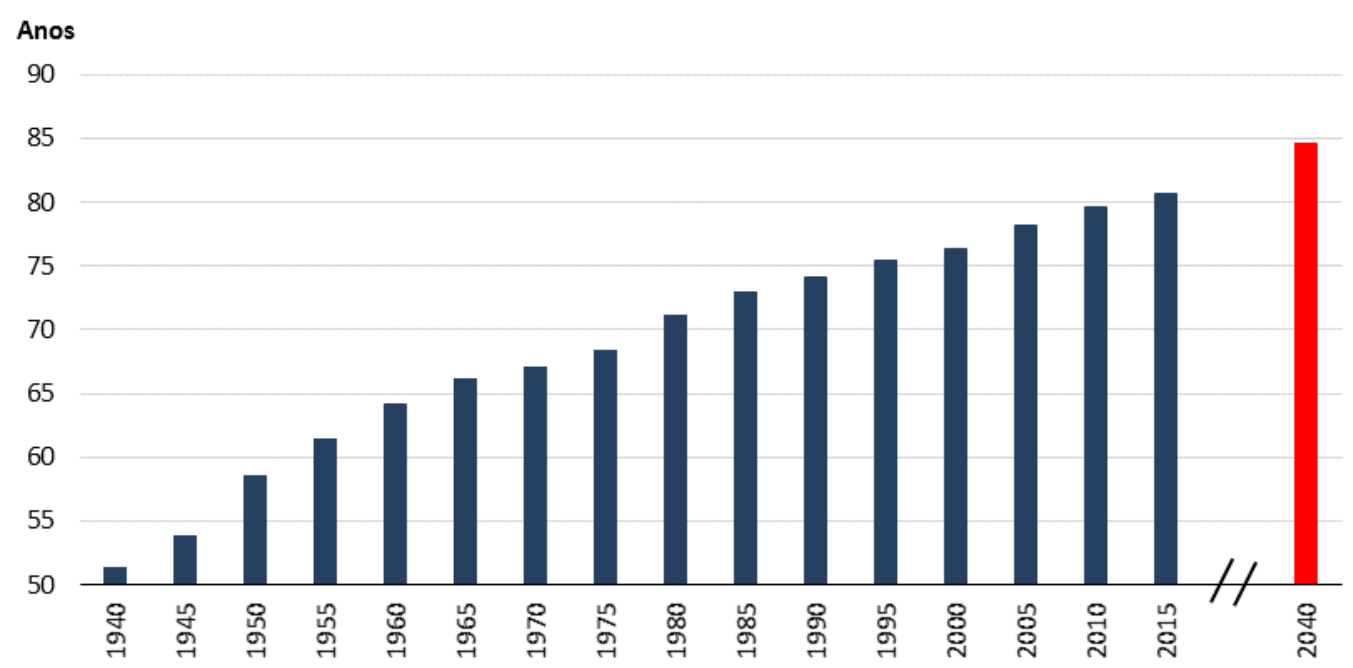

Figura 4 - Esperança de vida à nascença (1940-2040).

Fonte: Elaboração própria. Dados INE (2016); Clio Infra (2016); Castro et al. (2015).

Em determinados períodos, ciclos de vida mais longos significam taxas de mortalidade mais baixas (figura 5). Em Portugal no início do século XIX, as taxas de mortalidade rodavam os 30,3 óbitos por 1000 habitantes, mas desde 1960 que a taxa de mortalidade estacionou nos 10,1 óbitos por 1000 habitantes. A quebra da taxa de mortalidade global justifica-se sobretudo pela diminuição da taxa de mortalidade infantil.

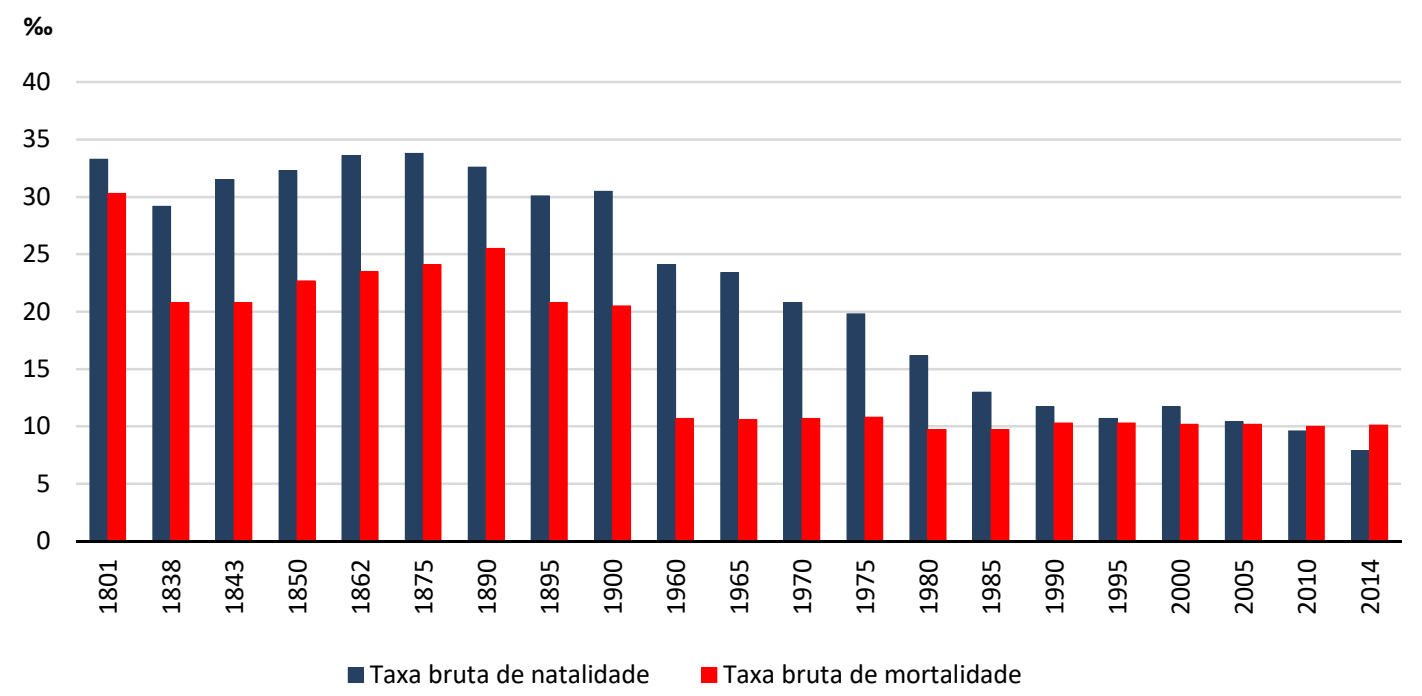

Figura 5 - Taxa de natalidade e mortalidade (1801-2014). Fonte: Elaboração própria. Dados PORDATA/INE - Estatísticas de Óbitos. 
Segundo o INE, em 1940, a esperança de vida à nascença rondava os 52 anos. Em 1950, a esperança de vida à nascença estava nos 58 anos, nos 55,8 anos para os homens e 61,0 para as mulheres. Em 2010, passa para os 80 anos, 76,7 anos para os homens e 82,5 para as mulheres. Para 2040, prevê-se que se aproxime dos 85 anos, 81,8 anos nos homens e 87,3 nas mulheres (Castro et al., 2015). Isto também significa que:

- em 1950, só 70\% dos homens conseguiam sobreviver até aos 50 anos, $42 \%$ até aos 70 anos e $9 \%$ até aos 85 anos. As mulheres vivem mais, 76\% conseguiam sobreviver até aos 50 anos, $56 \%$ até aos 70 anos e 13\% até aos 85 anos;

- em 2010, 94\% dos homens conseguiram sobreviver até aos 50 anos, 76\% até aos 70 anos e 32\% até aos 85 anos. As mulheres resistem muito mais, $97 \%$ conseguiam sobreviver até aos 50 anos, $89 \%$ até aos 70 anos e $54 \%$ até aos 85 anos;

- em 2040, 95\% dos homens vão conseguir sobreviver até aos 50 anos, 82\% até aos 70 anos e $48 \%$ até aos 85 anos. As mulheres terão um ciclo de vida ainda mais longo, $98 \%$ vão conseguir sobreviver até aos 50 anos, 93\% até aos 70 anos, $68 \%$ até aos 85 anos, e $7 \%$ até aos 100 anos.

Esta esperança de vida é justificada provavelmente pela diminuição das taxas de mortalidade, em todos os grupos etários (quadro 1). A quebra é brutal nos primeiros anos de vida. No sexo masculino, no 1 o ano de vida, as taxas diminuíram de 111,5 por mil habitantes, em 1950, para 3,3, em 2011. Nos quatro anos de vida seguintes, as taxas diminuíram de 13,6 por mil habitantes, em 1950, para 0,2 por mil habitantes, em 2011. Mas se acompanharmos os restantes grupos etários verificamos que entre 1950 e 2012 as taxas descem manifestamente, mesmo nas idades mais avançadas. Em 2040, as taxas de mortalidade são insignificantes nos primeiros 25 anos de vida e os que têm 85 a 89 anos mostram níveis de sobrevivência muito altos.

\begin{tabular}{c|c|c|c|c|c|c|c|c}
\multirow{2}{*}{} & \multicolumn{2}{|c|}{1950} & \multicolumn{2}{c|}{1990} & \multicolumn{2}{c|}{$\mathbf{2 0 1 2}$} & \multicolumn{2}{c}{$\mathbf{2 0 4 0}$} \\
\cline { 2 - 9 } & Masculina & Feminina & Masculina & Feminina & Masculina & Feminina & Masculina & Feminina \\
\hline $\mathbf{0 - 1}$ & 111,5 & 96,9 & 12,4 & 9,6 & 3,3 & 3,3 & 1,0 & 1,0 \\
\hline $\mathbf{1 - 4}$ & 13,6 & 13,1 & 0,9 & 3,3 & 0,2 & 0,2 & 0,0 & 0,0 \\
\hline $\mathbf{2 0 - 2 4}$ & 4,0 & 3,0 & 1,9 & 0,6 & 0,6 & 0,2 & 0,3 & 0,2 \\
\hline $\mathbf{5 0 - 5 4}$ & 12,3 & 7,1 & 7,8 & 3,6 & 5,9 & 2,2 & 5,4 & 1,7 \\
\hline $\mathbf{7 0 - 7 4}$ & 69,0 & 49,1 & 46,7 & 26,7 & 27,3 & 13,3 & 19,5 & 9,1 \\
\hline $\mathbf{8 5 - 8 9}$ & 235,2 & 190,0 & 196,7 & 158,0 & 153,3 & 117,4 & 80,2 & 65,1
\end{tabular}

Quadro 1 - Taxas de mortalidade masculina e feminina, em alguns grupos etários, por mil habitantes, em 1950, 1990, 2012 e 2040.

Fonte: Elaboração própria. Dados Castro et al. (2015), p. 112-113. 
Numa perspetiva longitudinal, o que é importante é o número de anos que um indivíduo vive. Como referimos, a mortalidade nas diferentes gerações é determinante, pois é crucial maximizar o número de indivíduos que chega à idade reprodutiva e a partir daí sobreviver o máximo de tempo para ter filhos.

A diminuição sucessiva nas taxas de mortalidade por grupos etários e os aumentos contínuos de esperança de vida vão-se refletir em estruturas etárias cada mais envelhecidas.

\section{Ciclos longos de vida e estruturas etárias estendidas}

A crise demográfica aparece com um significado sobretudo político e económico (Pérez Díaz, 2011). Reflete uma preocupação com os níveis de dependência. Mas se refletirmos convenientemente, o índice de dependência total em 1900 e mesmo em 1950 não eram muito diferentes do atual (figura 6). E em 1900, o número de dependentes relativamente à população potencialmente ativa era $90 \%$, tal como se estima que será em 2040. A situação atual é que é original, pois os potencialmente dependentes são quase $70 \%$ dos ativos.

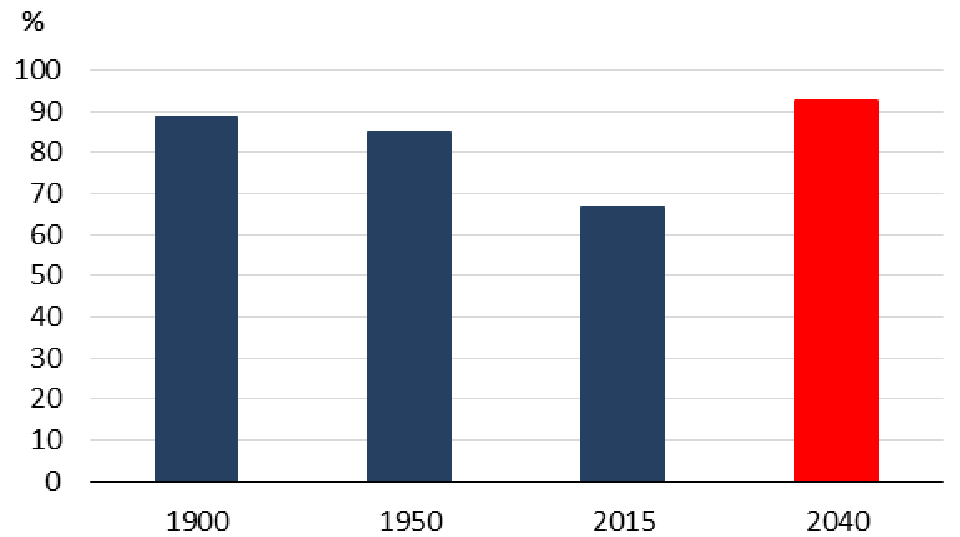

Figura 6 - Índice de dependência total, em 1900, 1950, 2015 e estimado para 2040. Fonte: Elaboração própria. Dados INE (2016); OCDE (2015).

Todo o discurso em torno do envelhecimento da população é como refere Eduardo Castro et al. (2015) alarmista, superficial e sem rigor, e pode-se acrescentar preconceituoso. 
Se a evolução científica e tecnológica continuar aos ritmos atuais, iremos possivelmente viver ainda mais anos de uma forma mais saudável. Além disso, o aumento da escolaridade irá repercutir-se na subida da produtividade dos ativos. Logo, Portugal tem de se focar nos investimentos para uma economia mais produtiva. Portugal não terá stocks de população em idade ativa disponíveis para uma estrutura produtiva intensiva em trabalho, logo tem de construir uma economia baseada em poucos recursos humanos, mas com elevados níveis de qualificações, numa economia mais intensiva em conhecimento, de maior produtividade (Castro et al., 2015).

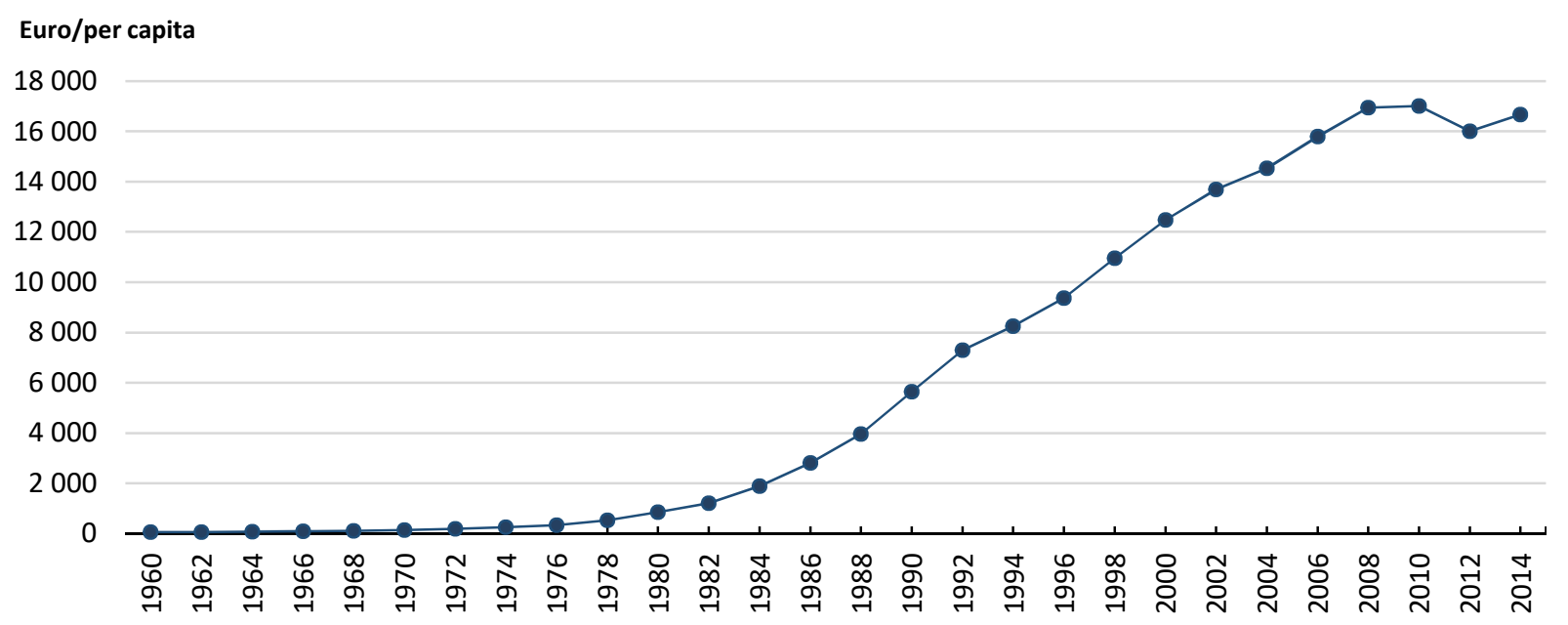

Figura 7 - Produto Interno Bruto (PIB) per capita (1960-2014).

Fonte: Elaboração própria. Dados PORDATA; INE (Contas Nacionais Anuais).

O facto de as populações viverem mais anos evidencia o resultado do desenvolvimento e da modernização de uma sociedade. Logo não é um problema e muito menos um sintoma de uma crise que precisamos de corrigir (Pérez Díaz, 2016), mas um desafio que as políticas públicas têm de ser capazes de responder. A nossa sociedade evoluiu num contexto em que a dependência dos mais jovens era uma realidade presente nas famílias e na estrutura de oferta de serviços de apoio público. Com a inversão da pirâmide, a importância dos dependentes idosos ganha uma grande expressão e as famílias e as políticas públicas têm de passar também a dirigir os seus recursos para os residentes que têm mais idade.

O que assistimos na Europa, dada a situação económica, é um discurso a favor da diminuição da despesa pública, que tende a privilegiar a transferência de alguns serviços públicos para a esfera dos privados, numa lógica de promover a atividade económica. Além 
disso, enfatiza-se a necessidade de diminuir o papel do Estado com a pseudo-desculpa da elevação dos custos associados ao envelhecimento demográfico.

É verdade que a população tem vindo a viver cada vez mais anos (figura 8). Em Portugal, em 2040, perspetiva-se que 32,4\% da população terá mais de 65 anos de idade, e 17,5\% mais de 75 anos (OCDE, 2015). Mas se uma população vive mais anos também tem também mais anos de vida ativa e de quotização de impostos, e ainda de poupança e de capacidade de investimento.

\section{Milhões}

12

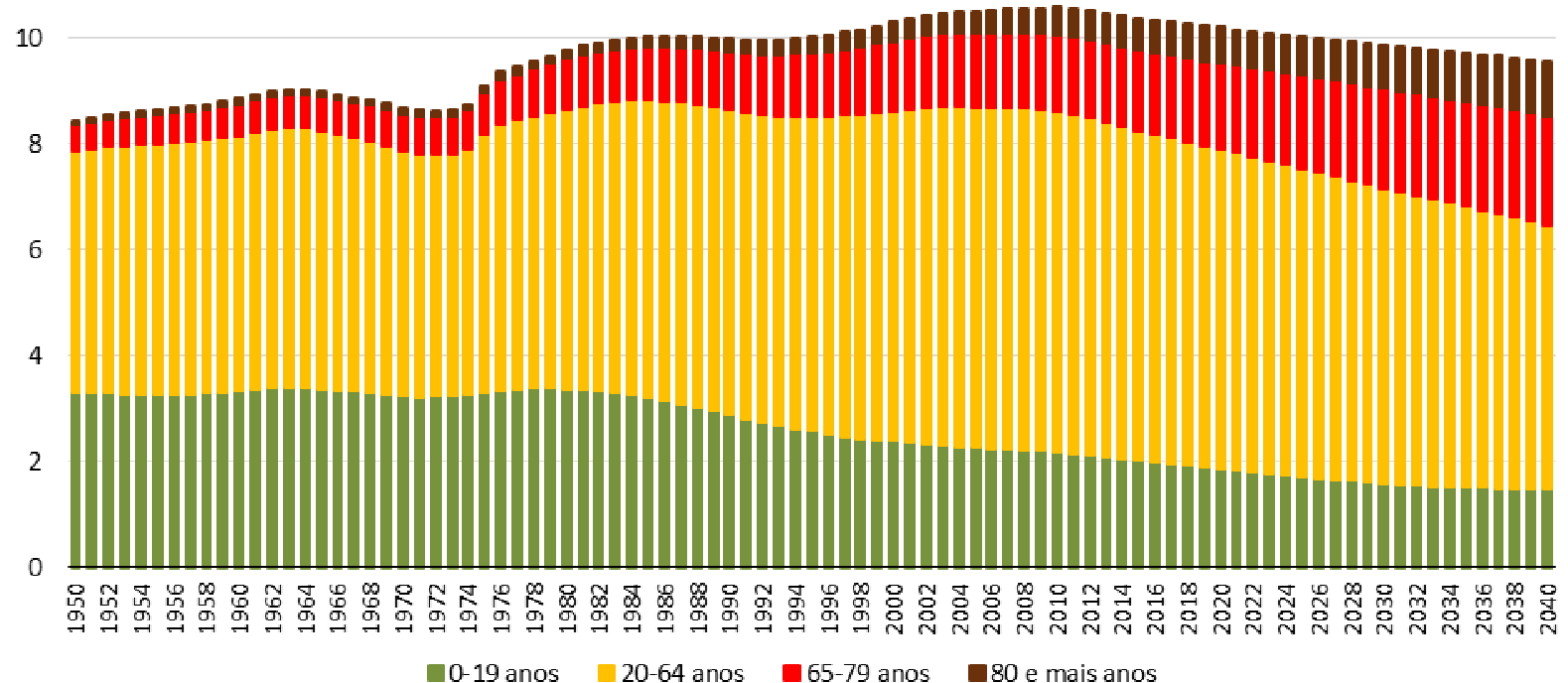

Figura 8 - População residente por grupos etários (1950-2040). Fonte: Elaboração própria. Dados OCDE (2015).

É certo que a população portuguesa tem vindo a aumentar e que o ciclo de vida é mais longo, mas, em termos territoriais, a questão coloca-se de outra forma: alguns territórios têm vindo a ganhar mais população que outros, e os que ganham atraem as populações mais jovens e ativas, logo os que estão a perder, estão a desfazer-se dos seus recursos reprodutivos e a hipotecar o seu futuro. Analisando os mapas da figura 9, verifica-se um claro envelhecimento das estruturas etárias das populações de um vasto território do país, sobretudo do interior. Portanto, o problema não está nos ciclos de vida longos ou nas estruturas etárias mais envelhecidas da população portuguesa, mas nas dinâmicas que se observam em determinados territórios. Insistentemente, em décadas sucessivas, um vasto território nacional esteve em perda demográfica, assistindo à saída das populações mais 
jovens. São décadas consecutivas de perdas de populações, de indivíduos que saem quando estão a entrar na idade fértil. Estas quebras contínuas são estruturalmente muito difíceis de inverter.

Simultaneamente, os territórios ganhadores (com uma estrutura etária mais jovem) estão cada vez mais circunscritos ao Noroeste português e à Região de Lisboa (figura 9). E isto não é nenhuma crise demográfica, mas uma dinâmica. No futuro a população portuguesa vai tendencialmente diminuir, logo poderá haver escassez de população em idade ativa e os territórios poderão concorrer ainda mais pelos recursos humanos escassos. E a concorrência será geral.

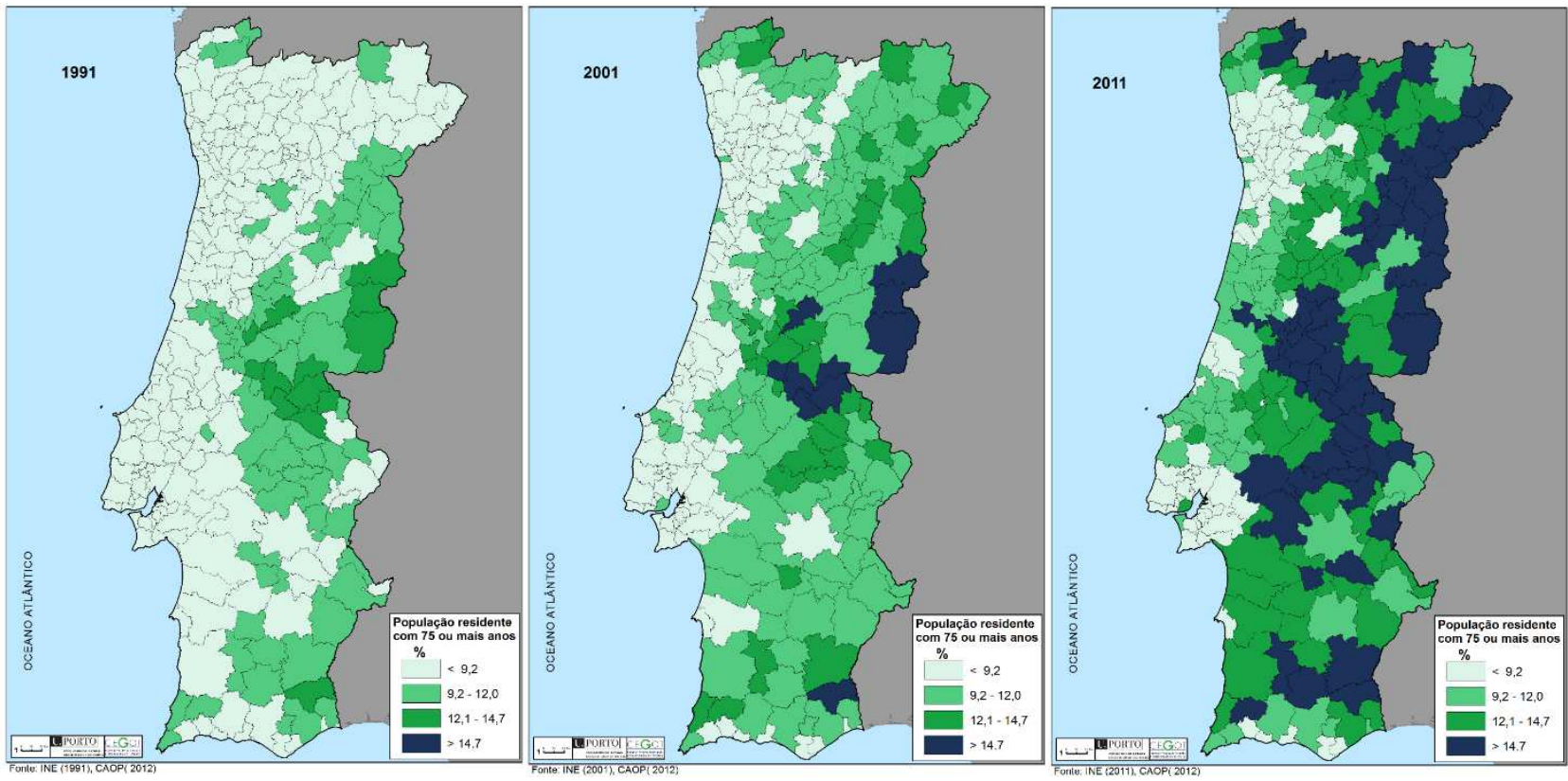

Figura 9 - População residente com mais de 75 anos (\%) por concelho, em 1991, 2001 e 2011. Fonte: Elaboração própria. Dados INE (Censos de 1991, 2001 e 2011).

\section{Eficiência reprodutiva}

A população é cada vez mais escolarizada e o acesso ao ensino é mais generalizado, nomeadamente para as mulheres, que se mantêm mais anos na escola e têm maior participação no mercado de trabalho e na sociedade em geral. A queda da fecundidade é o reflexo destas dinâmicas positivas. Em 40 anos, entre 1974 e 2014, o peso da mulher na população ativa aumentou de cerca de $40 \%$ para quase $50 \%$ (figura 10 ). Além disso, os 
níveis de escolaridade das mulheres têm aumentado a um ritmo bastante elevado (superior ao do homem) (figura 11), refletindo-se na diversificação das suas expectativas de vida, no adiamento ou no declínio da sua função reprodutiva, e no aumento da sua liberdade e do seu papel na sociedade.

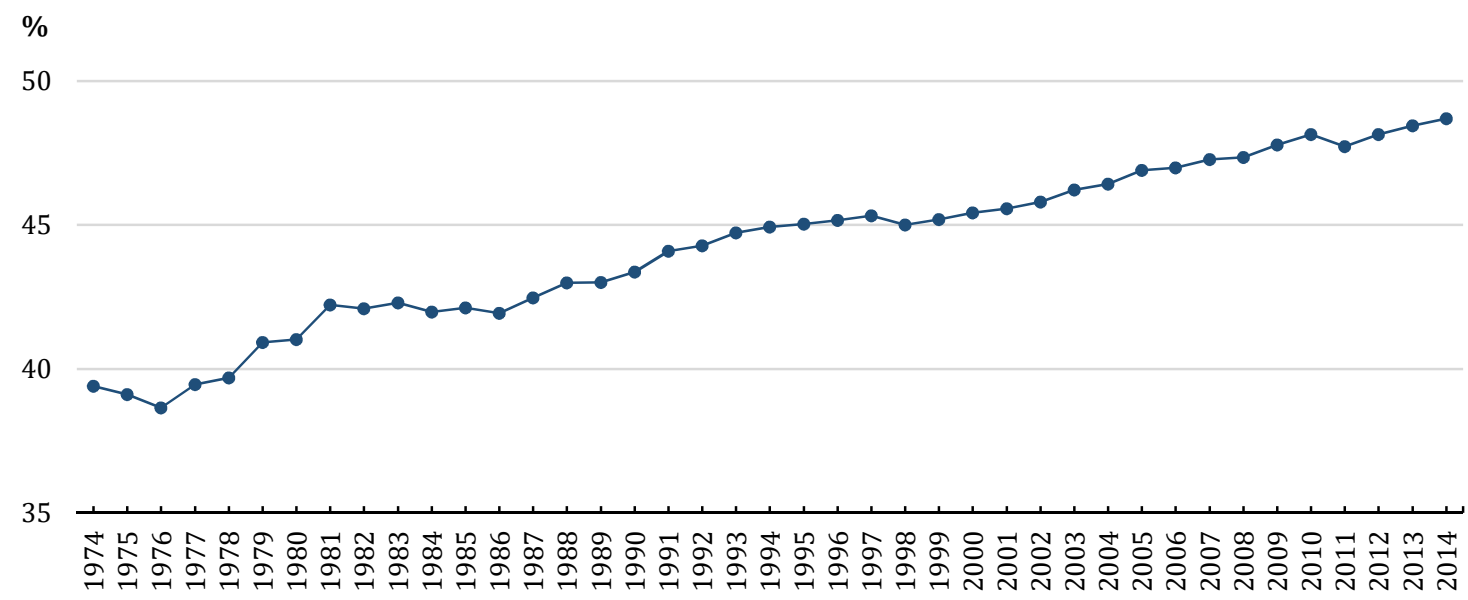

Figura 10 - Peso do sexo feminino na população ativa (1974-2014).

Fonte: Elaboração própria. Dados PORDATA; INE (Indicadores Demográficos).

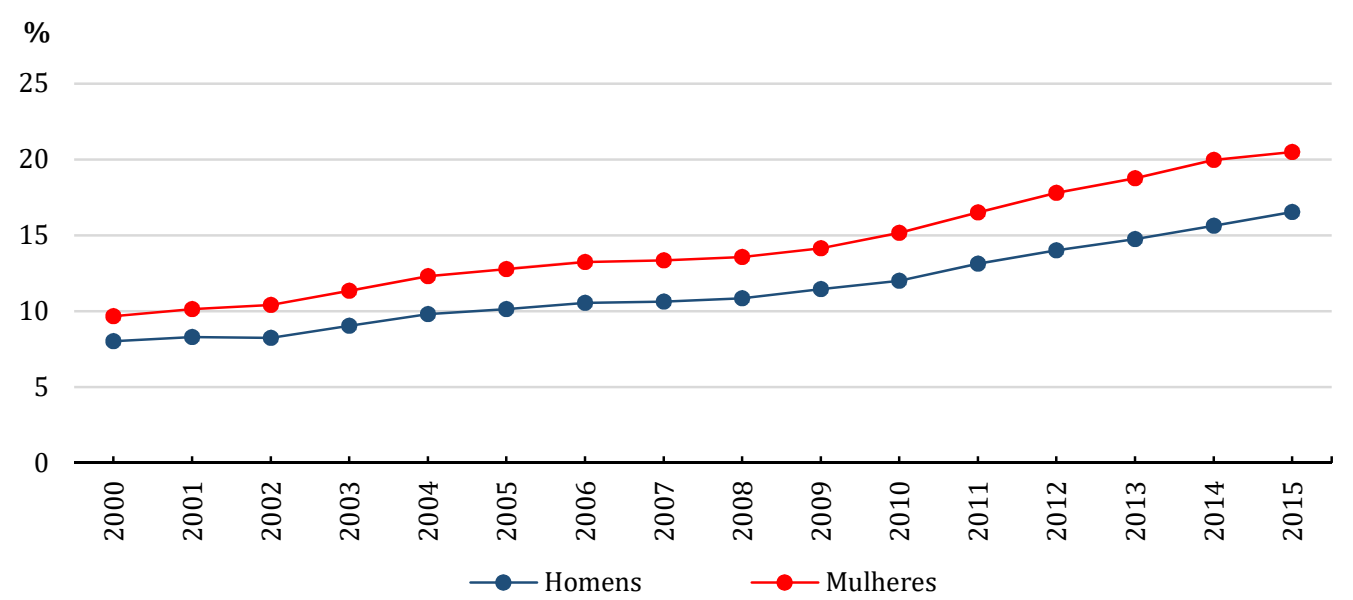

Figura 11 - População residente com 15 ou mais anos com escolaridade igual ou superior ao secundário, no total da população com 15 ou mais anos, por sexo (2000-2015). Fonte: Elaboração própria. Dados PORDATA; INE (Indicadores Demográficos).

Esta mudança vai refletir-se diretamente na diminuição da fecundidade (figura 12 e 13). Mas Portugal tem a segunda taxa de fecundidade mais baixa do mundo e a mais baixa da União Europeia, o que reflete também as grandes mudanças que o país atravessou nas últimas décadas e as expectativas que as famílias depositam nos seus filhos. Desde 1960 que o número médio de filhos por mulher regista uma tendência decrescente: em 1960, a média 
nacional era de 3,16 filhos por mulher e, em 2014, a média nacional situava-se em 1,23 filhos por mulher (a média da União Europeia era de 1,58). Para 2040, perspetiva-se que o valor nacional aumente para 1,6 filhos por mulher (figura 12).

Territorialmente, as mudanças são significativas (entre 2001 e 2014). Há uma clara diminuição do índice sintético de fecundidade por toda a superfície do território português, sobressaindo-se, em 2014, apenas algumas das áreas mais urbanas (sobretudo em torno de Lisboa) e algumas cidades médias (figura 13), que apresentam valores superiores à média nacional.

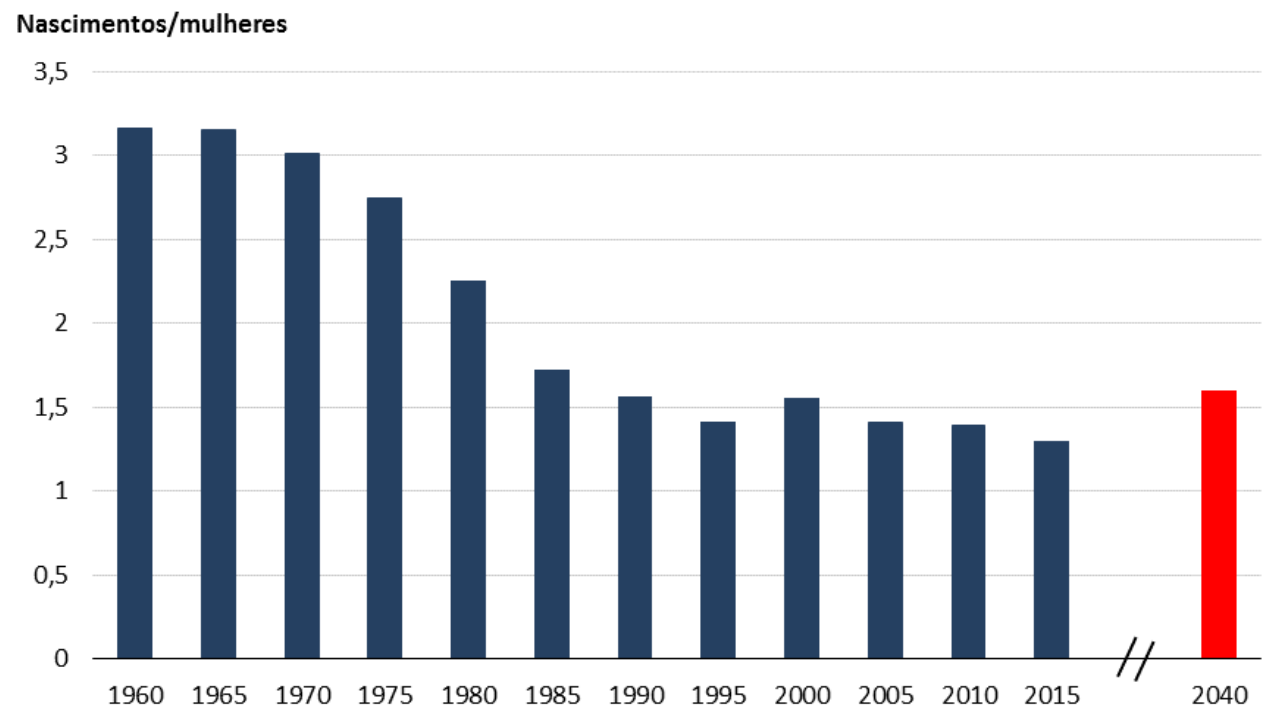

Figura 12 - Índice sintético de fecundidade (1960-2040).

Fonte: Elaboração própria. Dados PORDATA; INE (Indicadores Demográficos); Castro et al. (2015). 

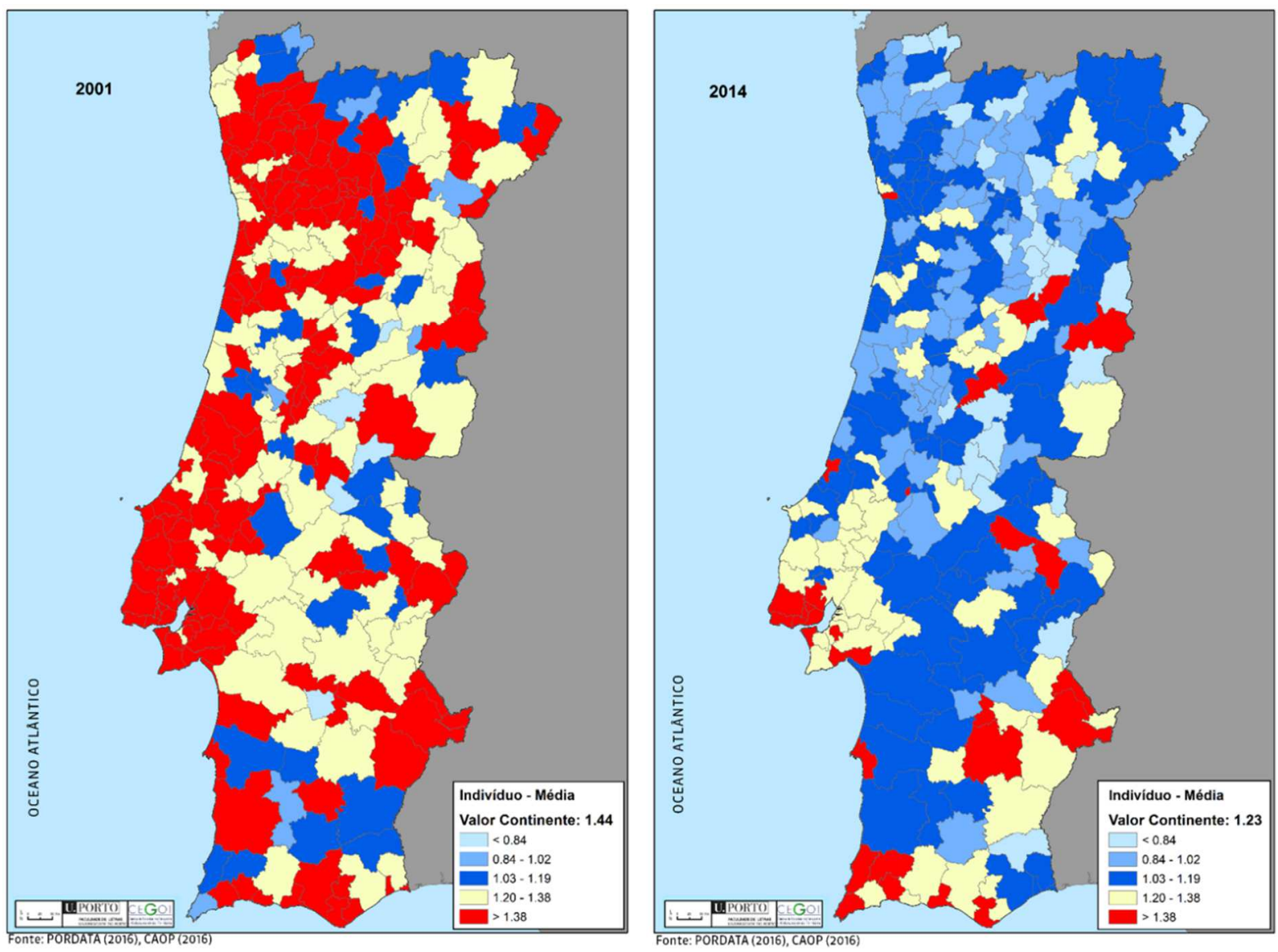

Figura 13 - Índice sintético de fecundidade, em 2001 e 2014.

Fonte: Elaboração própria. Dados PORDATA; INE (Indicadores Demográficos).

Mas seguindo, a "teoria da eficiência reprodutiva" (Macinnes e Pérez Díaz, 2008; 2009), a modernização demográfica pressupõe um reforço da "eficiência reprodutiva". Deve-se observar a população como um sistema dinâmico, analisando a quantidade de nascimentos, em cada momento temporal, necessários para uma população se manter. A fecundidade é importante, mas não é o central, porque o que é determinante é o tempo que cada indivíduo vai viver. A diminuição da taxa de mortalidade infantil, no primeiro ano e até aos cinco anos, vão ser decisivas (figura 14).

Como já se referiu, Portugal foi exemplar na sua diminuição de mortalidade, pois nos anos sessenta faleciam por ano entre 12 a 19 mil dos nados vivos, e atualmente as possíveis ocorrências são claras exceções. A taxa de mortalidade infantil, em 1960 era de 77,5\%o, enquanto em 2014 passa para 3\%o (figura 14). Com a quebra de mortalidade nos primeiros anos de vida, a sobrevivência aumentou para aqueles que passaram a chegar à idade de procriar. Logo, para a mesma dimensão populacional passou-se a precisar de menos nascimentos. Esta revolução é intergeracional, porque se uma geração sobrevive vai 
contribuir de uma forma mais eficaz para a sua reprodução, e assim sucessivamente. Tratase de um ciclo acumulativo que se reflete numa revolução demográfica.

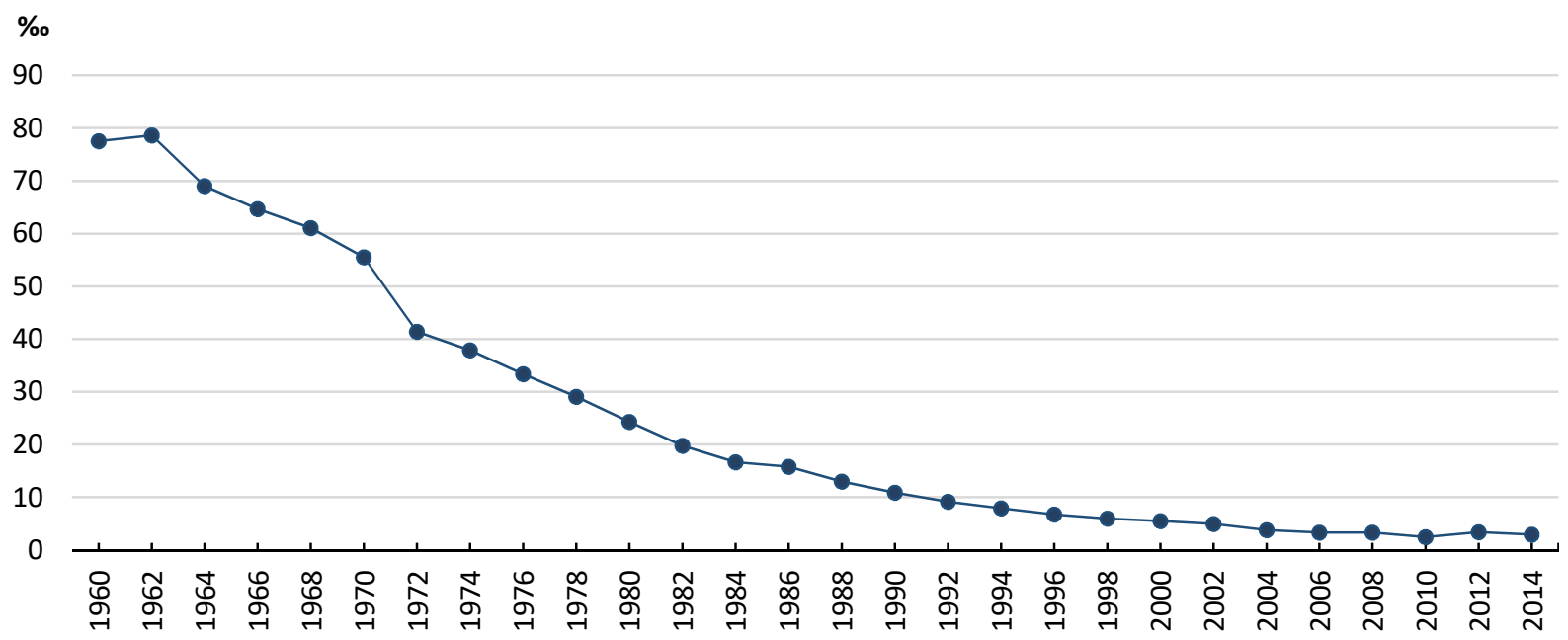

Figura 14 - Taxa de mortalidade infantil (1960-2014).

Fonte: Elaboração própria. Dados PORDATA; INE (Estatísticas de Óbitos).
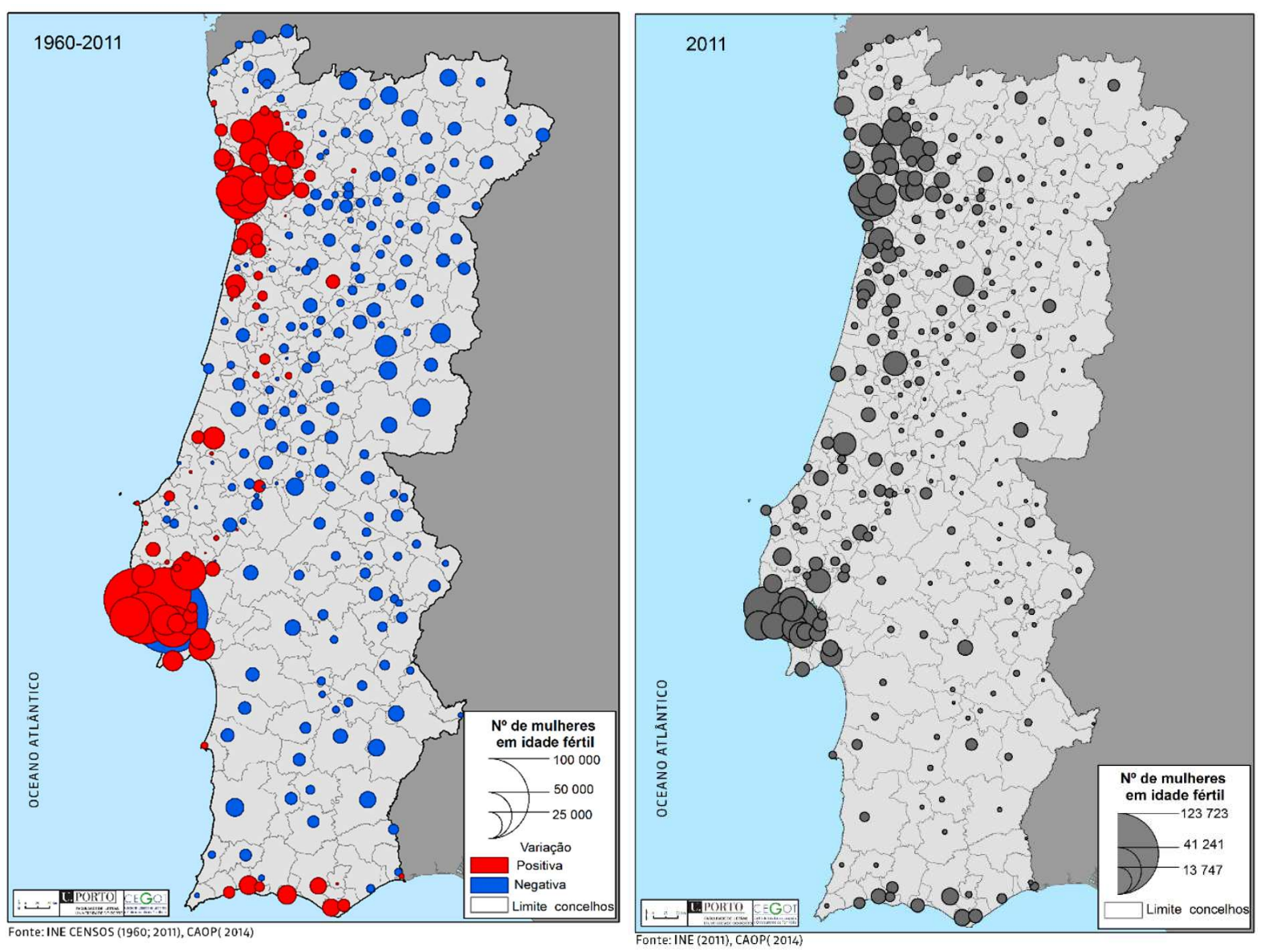

Figura 15 - Mulheres em idade reprodutiva em 2011 e evolução entre 1960 e 2011. Fonte: Elaboração própria. Dados PORDATA; INE (Censos 1960 e 2011). 


\begin{tabular}{c|c|c|c|c|c|c} 
Idades & $\mathbf{1 9 5 0}$ & $\mathbf{1 9 8 1}$ & $\mathbf{2 0 1 1}$ & $\mathbf{2 0 4 0}$ & $\mathbf{1 9 5 0 / 2 0 1 1}$ & $\mathbf{2 0 1 1 / 2 0 4 0}$ \\
\hline $\mathbf{1 5 - 1 9}$ & $\mathbf{4 0 6} 605$ & $\mathbf{4} 26087$ & 276725 & 211431 & $-31,9$ & $-23,6$ \\
\hline $\mathbf{2 0 - 2 4}$ & 381563 & 382511 & 289042 & 209353 & $-24,2$ & $-27,6$ \\
\hline $\mathbf{2 5 - 2 9}$ & 346636 & 342787 & 331228 & 219866 & $-4,4$ & $-33,6$ \\
\hline $\mathbf{3 0 - 3 4}$ & 277950 & $322 \mathbf{2 6 7}$ & 394833 & 241158 & 42,1 & $-38,9$ \\
\hline $\mathbf{3 5 - 3 9}$ & 294118 & 296464 & 422376 & 279628 & 43,6 & $-33,8$ \\
\hline $\mathbf{4 0 - 4 4}$ & 276757 & 300886 & 398136 & 309530 & 43,9 & $-22,3$ \\
\hline $\mathbf{4 5 - 4 9}$ & 249147 & 308883 & 399305 & 307900 & 60,3 & $-22,9$ \\
\hline Total & $\mathbf{2 2 3 2 7 7 6}$ & $\mathbf{2} \mathbf{3 7 9} \mathbf{8 8 5}$ & $\mathbf{2 5 1 1 6 4 5}$ & $\mathbf{1 7 7 8 ~ 8 6 6}$ & $\mathbf{1 2 , 5}$ & $\mathbf{- 2 9 , 2}$
\end{tabular}

Quadro 2 - Mulheres em idade reprodutiva em 1950, 1981, 2011 e 2040 (prospetivas) e variações $1950 / 2011$ e $2011 / 2040$.

Fonte: Elaboração própria. Dados INE (Censos de 1950 a 2011); Castro et al. (2015).

Logo o problema não está só na quebra da fecundidade, mas na dimensão da população em idade reprodutiva. A nível nacional, entre 1950 e 2011, o território português não diminuiu o número de mulheres em idade fértil (quadro 2). No entanto, em termos territoriais, as áreas de baixa densidade têm uma dimensão muito fraca de população feminina em idade fértil devido às variações regressivas, o que compromete o ciclo reprodutivo, independentemente dos níveis de fecundidade. A variação sistemática da população em idade fértil, nos últimos cinquenta anos em determinados territórios, construiu um país claramente dualizado, com as regiões metropolitanas a ganharem mulheres em idade reprodutiva e uma grande superfície do país a perder claramente, mesmo a grande maioria das cidades médias (figura 15).

\section{Um balanço e uma visão para o futuro}

Se analisarmos com atenção a evolução do saldo natural e do saldo migratório verificamos que o saldo natural desde 1960 tem vindo progressivamente a perder importância e nos últimos anos, desde 2012, já tem um comportamento negativo o que significa que a natalidade não está a conseguir compensar os níveis de perdas da mortalidade (figura 16). 


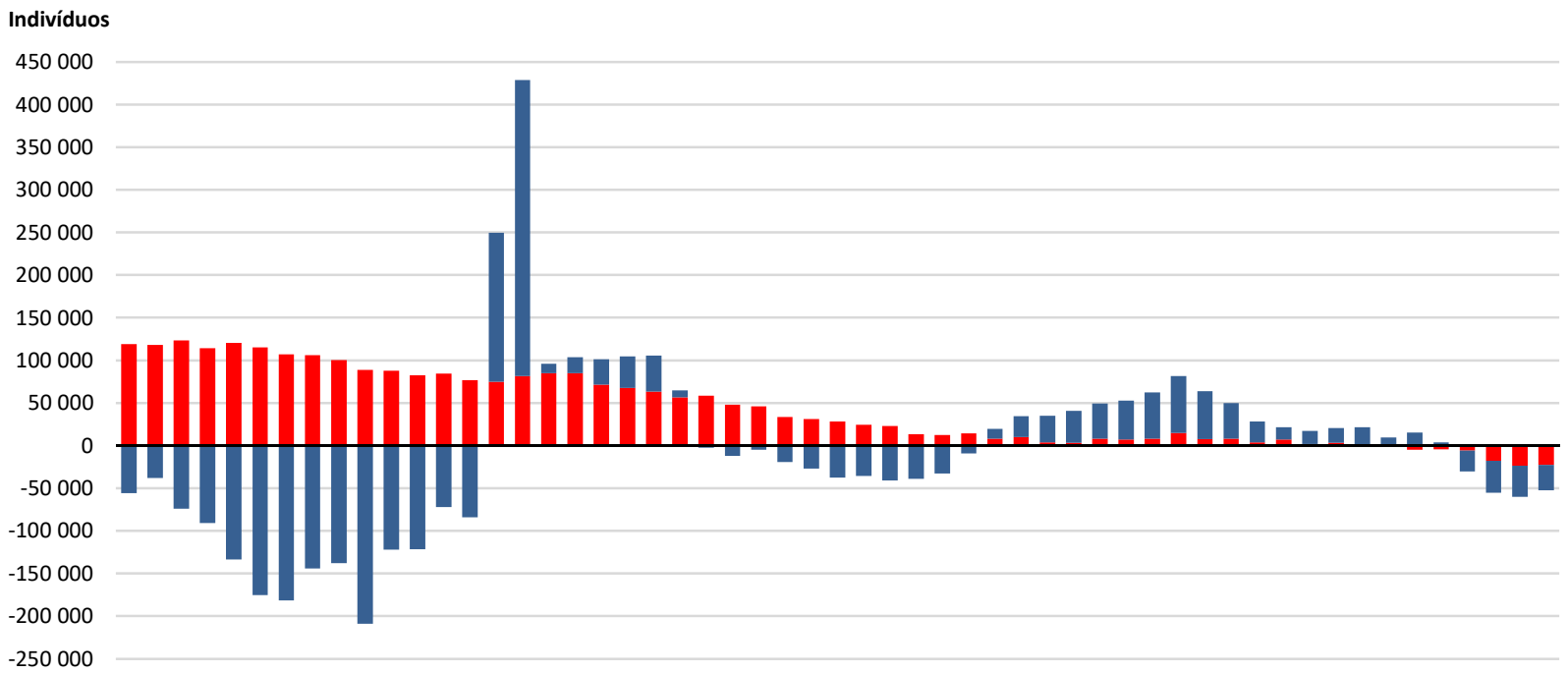

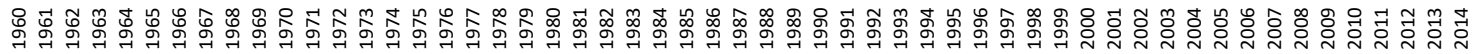

- Saldo natural $\quad$-Saldo migratório

Figura 16 - Saldo natural e migratório, 1960-2014.

Fonte: Elaboração própria. Dados PORDATA; INE (Indicadores Demográficos).
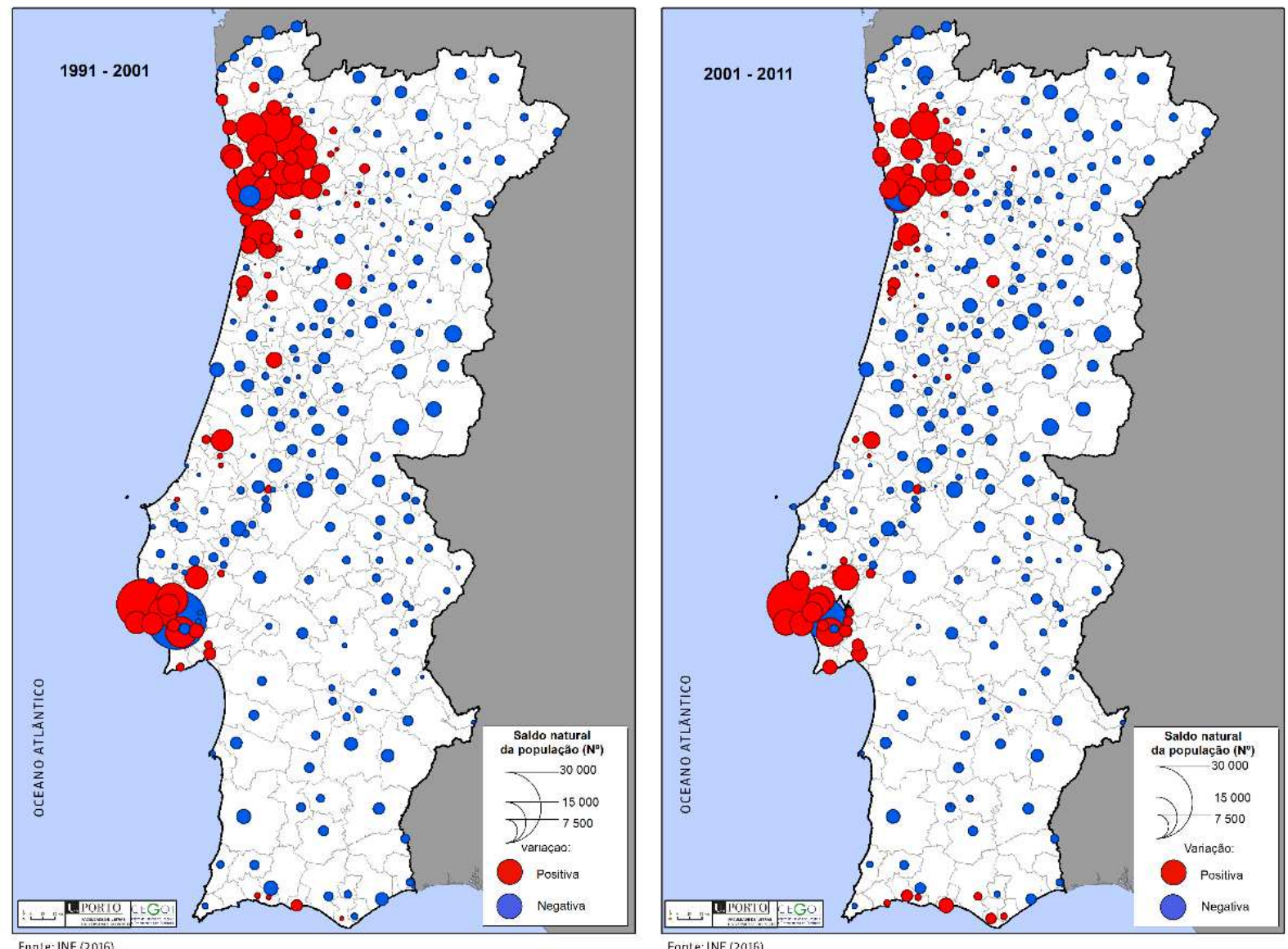

Figura 17 - Saldo natural, 1991-2001 e 2001-2011.

Fonte: Elaboração própria. Dados INE (Nascimentos e Óbitos anuais, 1991-2011). 
A análise territorial acrescenta muita informação à leitura destes processos. Na década de oitenta e noventa, o saldo natural de Lisboa e o Porto é claramente negativo (sobretudo nos anos 90), mas os territórios urbanos envolventes mostram um dinamismo demográfico evidente, ainda que evidenciam uma tendência para diminuírem. No resto do país o saldo natural é claramente negativo mesmo para a maioria das cidades médias (só muito poucas apresentam um saldo positivo, nomeadamente Aveiro, Viseu, Coimbra e Leiria) (figura 17).

O saldo migratório tem, no entanto, mostrado um comportamento bastante flutuante (figura 16). Nos últimos 50 anos, os movimentos migratórios tiveram um impacto muito significativo na evolução da população portuguesa. Nos anos sessenta e inícios dos anos setenta do século passado, a sangria emigratória repercutiu-se em saldos migratórios claramente negativos. Entre 1960 e 1973, o saldo migratório significou uma perda de 1.639.559 indivíduos. Com a revolução de 25 de abril em 1974, sobretudo com o retorno das populações que estavam nas ex-colónias, o processo inverteu-se e em 1974 e 1975 o saldo migratório traduziu-se num saldo claramente positivo de mais de 520.000 indivíduos. Nos anos oitenta e noventa (entre 1982 e 1992) o saldo migratório volta a ser negativo (menos 261.141 indivíduos), mas nos anos noventa (a partir de 1993) regressa aos valores positivos refletindo a atratividade da base económica fruto dos investimentos financiados pelos fundos europeus.

Em termos territoriais pode-se verificar sinteticamente o seguinte (figura 18) nas duas últimas décadas:

- Lisboa e o Porto perdem população pelos saldos migratórios, na década de noventa na ordem dos 140.000 indivíduos.

- no Continente, no total, na década de noventa temos 188 concelhos com um saldo migratório positivo e 90 com um saldo migratório negativo. Entre 2001 e 2011, a situação piorou, pois, os saldos migratórios positivos enfraqueceram claramente por todo o país, nas regiões metropolitanas, por todo o litoral e nas cidades médias.

Globalmente, a nível concelhio, entre 1991 e 2001, no Continente 125 concelhos registaram um crescimento populacional positivo e 151 negativo. Enquanto 2 concelhos mantiveram a população. Entre 2001 e 2011, o número de concelhos perdedores aumentou. Em 182 
concelhos registou-se um declínio populacional e 96 um decréscimo da população residente. Isto demonstra o processo centrifugador que o país registou: cada vez mais concelhos a perder, e cada vez menos a ganhar.

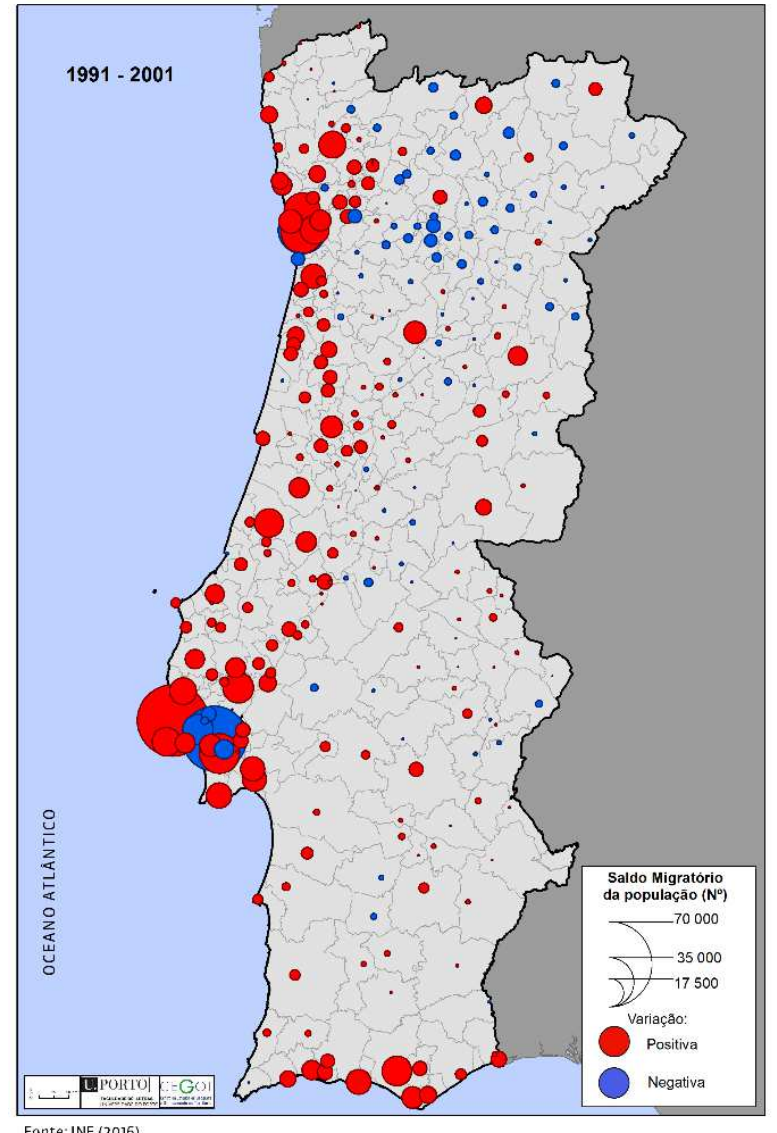

Figura 18 - Saldo migratório, 1991-2001 e 2001-2011.

Fonte: Elaboração própria. Dados INE (Nascimentos e Óbitos anuais, 1991-2011).

Territorialmente, sempre fomos mais povoados a norte que a sul, no litoral do que no interior. Além disso, os diferentes processos demográficos têm mostrado comportamentos muito diversificados ao longo do tempo e a nível territorial. Por isso, temos de refletir os diferentes desafios ancorados no tempo e nos territórios, no passado e no presente, para coletivamente conseguir-se construir o futuro. Assim, em termos de cenários para o futuro, a leitura global e territorial revela-nos um país a diferentes velocidades.

Segundo as projeções demográficas (para 2040, Castro et al., 2015; para 2050, a OCDE, 2015), a população portuguesa vai diminuir, com intensidades diferentes segundo os cenários. A diminuição populacional vai ter impactos na estrutura etária dos diferentes territórios, reforçando a concentração populacional e a atratividade das populações em 
idade fértil para determinadas áreas geográficas do país (sobretudo os espaços metropolitanos) e intensificando a redução populacional, nomeadamente das populações em idade fértil, numa extensa superfície do território nacional (figura 19). Os mais jovens e mais qualificados serão atraídos pelos territórios com uma oferta superior de oportunidades, mais diversificada e com melhores remunerações.
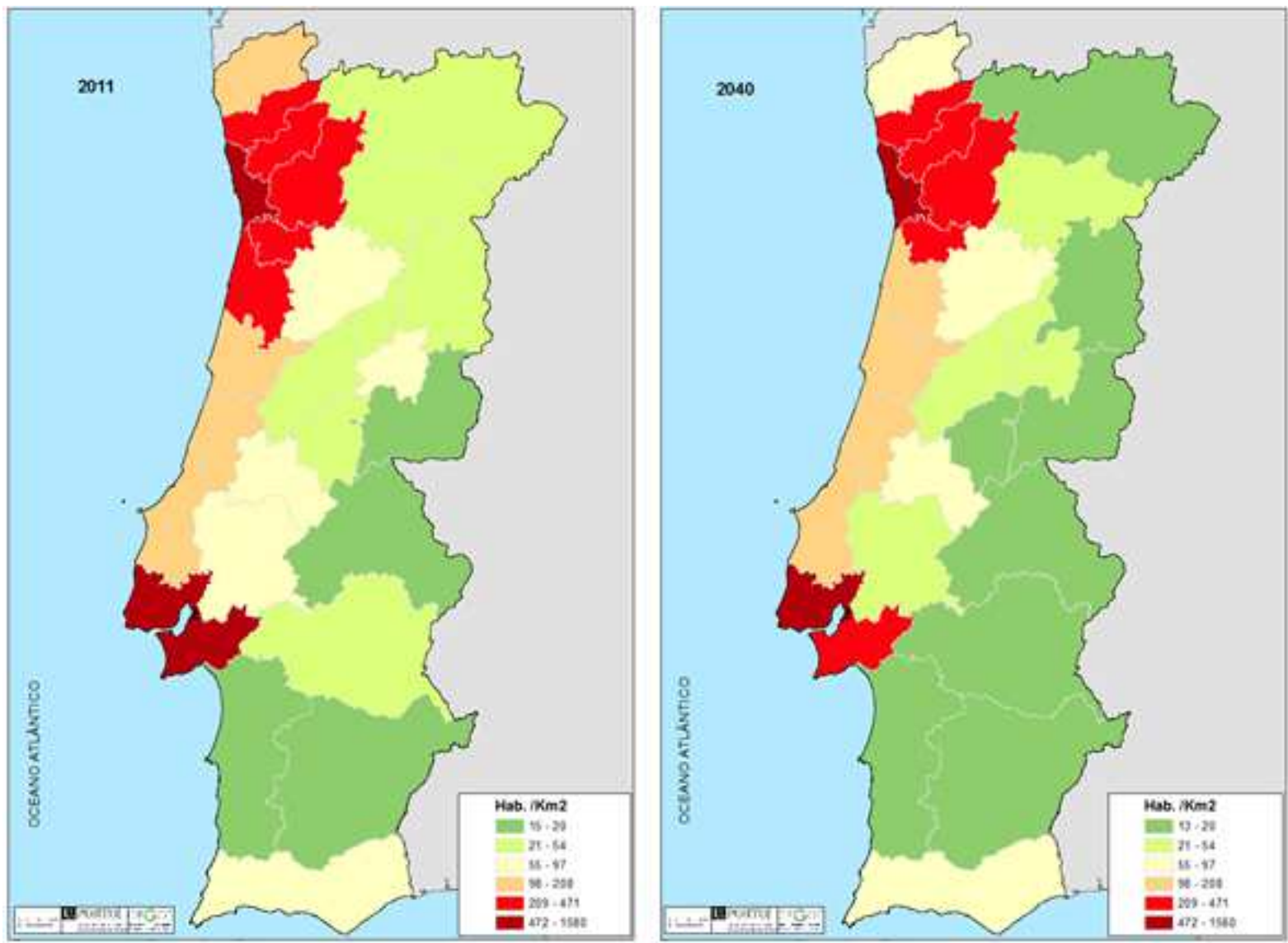

Figura 19 - Densidade populacional por NUT III, 2011 e 2040.

Fonte: Elaboração própria. Dados INE (Censos 2011); Castro et al. (2015), p. 188 (cenário intermédio).

Os territórios de baixa densidade, menos populosos terão grandes dificuldades em responder a bases económicas que sejam intensivas em trabalho. Parece que a solução passará por refletirmos de que forma podemos construir uma economia baseada na qualidade e não na quantidade de recursos humanos, numa economia intensiva em conhecimentos e de maior produtividade. Dificilmente seremos capazes de reverter estas situações. A sociedade e o território mudaram, logo os desafios devem ser reequacionados. 
O aumento da fecundidade para valores próximos dos europeus é pertinente, mas só teria impactos daqui a vinte ou trinta anos. Mas o aumento de fecundidade só teria impactos significativos nos territórios que concentram um maior volume de população em idade fértil, sobretudo mulheres. Nos territórios de baixa densidade o seu efeito seria crucial, mas exíguo, pois o número de mulheres em idade fértil é muito baixo.

O reforço da atratividade residencial de Portugal pode ter efeitos mais imediatos. Nos territórios de baixa densidade é crucial porque só a atratividade residencial de populações em idade fértil poderá ajudar a inverter as décadas de perdas migratórias (décadas sucessivas que viram os mais jovens ativos partirem). Mas o reforço de atratividade depende de muitas variáveis sociais, económicas, políticas e culturais, a maioria delas incontroláveis num mundo cada vez mais global.

Assim, não temos uma demografia para uma economia intensiva em trabalho, como todos os países desenvolvidos e avançados na modernização demográfica. Portugal tem de apostar na atratividade e na educação e ciência (Castro et al., 2015) para construirmos um país mais competitivo e simultaneamente mais coeso, com uma população residente mais qualificada e com melhor qualidade de vida. E isto passa por uma atenção especial à necessidade de políticas públicas mais integradas, centradas nas pessoas e na evolução dos territórios. E aqui a demografia é central e tem sido muito descurada pelas políticas públicas.

Podemos finalmente concluir que a modernização demográfica não é em si só um problema. Devemos reconhecer a importância crescente das pessoas idosas na população em geral e refletir os desafios e as respostas que devem ser equacionadas. Neste âmbito, a sociedade tem de se adaptar às necessidades das populações mais idosas tendo em vista garantir a sua autonomia e qualidade de vida, tendo em atenção um conjunto de necessidades: apoiar as pessoas idosas que desejam viver nas suas habitações de forma independente (adaptação das habitações ou partilha do alojamento); garantir o acesso aos serviços de proximidade das populações idosas e com menor mobilidade; promover ambientes urbanos amigos de todas as gerações, nomeadamente através de espaços públicos mais acolhedores e acessíveis; facilitar a mobilidade adaptando as redes de transportes, pois são uma condição para a sua autonomia; promover a atividade física e 
desportiva e uma alimentação favorável a uma vida mais extensa e com maior qualidade; olhar para o envelhecimento enquanto uma oportunidade de crescimento económico, criação de novos serviços e emprego e capacidade de poupança e consumo; estimular a participação social dos mais idosos, através do voluntariado e do desenvolvimento de atividades intergeracionais e de uma maior sensibilização para a utilização de tecnologias de informação e comunicação. O peso demográfico dos idosos abre novos desafios à sociedade contemporânea.

\section{Referências bibliográficas}

AVDEEV, A., EREMENKO, T., FESTY, P., GAYMU, J., LE BOUTEILLEC, N., SPRINGER, S. Populations et tendances démographiques des pays européens (1980-2010). Population, 2011, vol. 66, no1, p. 9-133.

BANDEIRA, M., AZEVEDO, A., GOMES, C., et al. Dinâmicas Demográficas e Envelhecimento da População Portuguesa. 1950-2011 Evolução e Perspetivas. [online]. Lisboa: Fundação Francisco Manuel dos Santos. 2014. Disponível em: https://www.ffms.pt/upload/docs/dinamicas-demograficas-e-envelhecimento-dapopulac_efe8FbqdjUGZx3LduUIzgg.pdf

CASTRO, E., MARTINS, J., SILVA, C. A Demografia e o País: Previsões Cristalinas sem Bola de Cristal. Lisboa: Gravida. 2015. ISBN: 9789896166564.

DASGUPTA, P.S. On the concept of optimum population. The Review of Economic Studies, 1969, vol. 36, no 3, p. 295-318.

ESPON. DEMIFER - Demographic and Migratory Flows affecting European Regions and Cities. 2010. [online]. Disponível em:

https://www.espon.eu/main/Menu_Projects/Menu_ESPON2013Projects/Menu_AppliedResearch/ET2050.htm I

ESPON. Demographic trends and scenarios (vol. 2). [online]. ET2050 - Territorial Scenarios and Visions for Europe. 2014. Disponível em:

https://www.espon.eu/main/Menu_Projects/Menu_ESPON2013Projects/Menu_AppliedResearch/demifer.ht $\mathrm{ml}$

FERRÃO, J., ANDRÉ, I, MALHEIROS, J., MARQUES, T., PINTO-CORREIA, T. População e Território (Parte II). In MEDEIROS, C. Geografia de Portugal: Sociedade, Paisagens e Sociedades. Lisboa: Círculo de Leitores, 2005, p. 49-140.

MACINNES, J., PÉREZ DÍAZ, J. La tercera revolución de la modernidad: la reproductiva. Revista española de investigaciones sociológicas, no 2008, 122, p. 89-118.

MACINNES, J., PÉREZ DÍAZ, J. The reproductive revolution. The Sociological Review, 2009, vol. 57, no 2, p. 262284.

MACINNES, J., PÉREZ DÍAZ, J. Transformations of the World's Population: the Demographic Revolution. In TURNER, B. The Routledge International Handbook of Globalization Studies: Wiley-Blackwell, 2008, p. 137-161. 
MARQUES, T., MAIA, C., RIBEIRO, D., SANTOS, H. A demografia na construção de uma visão temporal e territorial de Portugal. In "V Congresso Português de Demografia - A Crise Demográfica: Um País em Extinção?”. Lisboa: Fundação Calouste Gulbenkian, 6-7 de outubro de 2016.

OCDE (2015), How's Life? 2015: Measuring Well-being. Paris: OCDE Publishing. DOI: 10.1787/how_life-2015en. ISBN: 9789264211018.

PÉREZ DÍAZ, J. La Madurez de Masas. 2002. [online]. Disponível em: http://www.eumed.net/cursecon/libreria/MadurezMasas.pdf.

PÉREZ DÍAZ, J., ABELLÁN GARCÍA, A. Demografía, envejecimiento y crisis ¿Es sostenible el Estado de Bienestar? In El Estado de bienestar en la encrucijada: nuevos retos ante la crisis global: Federación de Cajas de Ahorros Vasco-Navarras, 2015, p. 47- 62.

PÉREZ díAZ, J., ABELLÁN GARCÍA, A. Envejecimiento y dependencia. In TORRES ALBERO, C., España 2015. Situación Social. Madrid: CIS, 2015, p. 148-157.

ROSA, M. O Envelhecimento da Sociedade Portuguesa. Lisboa: Fundação Francisco Manuel dos Santos. 2012. ISBN: 9789898424471

ROSA, M., CHITAS, P. Portugal: os Números. 2ª ed.. Lisboa: Fundação Francisco Manuel dos Santos. 2010. ISBN: 9789898424051.

SAUVY, A. Les conséquences du vieillissement de la population. La France ridée; Echapper à la logique du déclin. Paris, 1979, p. 61-118.

SAUVY, A. Vieillesse des nations. Paris: Gallimard. 2001. ISBN: 9782070758449. 